\title{
Contemporary Data Science for Finance Students: A Comparative Study of Essential Features of Commonly Used Statistical Software
}

\author{
1 Madalina Viorica Manu, ${ }^{2}$ Ilie Vasile \\ ${ }^{1,2}$ Bucharest University of Economic Studies, Romania
}

\begin{abstract}
In this paper we compare some of the essential traits of the software preferred by researchers, students and professors, such as R or RStudio, or Matlab. In order to fill the gap in the Romanian literature and help finance students in choosing proper tools according to the research purpose, this comparative study aims at bringing a fresh, useful perspective in the relevant literature. In Romania, the use of $\mathrm{R}$ was the focus of several international conferences on official statistics held in Bucharest, and others having business excellence, innovation and sustainability as purpose, while Eviews is recommended and taught by the Romanian professors. In this time, at global scale, R programming language is considered the lingua franca of data science, as common statistical software used both in corporations and academia. In this paper, I analyze basic features of such software, with the purpose of application in finance.
\end{abstract}

Keywords: Poftware, Programming language, R, RStudio, Statistics

\section{Introduction}

Data science teams, economists and corporations use a mix of languages, often, at least $R$ and Python ( $R$ for Data Science n.d.). The Python Programming Language ranks 4, climbing one step in the last year, while $\mathrm{R}$ is in ascension, ranking 10 in the popularity of programming languages; however, MATLAB programming language is falling, ranking the 18th. (TIOBE 2020)

\subsection{Problem Statement}

Comparisons of finance problems solving using MATLAB, R or Eviews represent an area of research that is not yet developed, although small steps have been made in Romania (Simionescu 2014). The use of $R$ was the central theme of several international conferences on official statistics, organized by R-omania Team in Bucharest since 2013 (R Project R-omania Team n.d.).

\subsection{Aim of the Study}

This paper is a comparative study of the most used software instruments for modeling, in an attempt to understand their main features and then define a model for the enterprise value. This research can / should be extended as there are books and many tutorials and courses for an in-depth study of software instruments for modeling and analyzing finance phenomena.

In the context of machines getting smarter, there is a strong need for continuous, lifelong learning in general and even more, in finance. We should keep in mind that the ability to adapt skills to the changing needs of the workplace will be critical for the employees and lifelong learning, ${ }^{1}$ a must. However, the reality falls far short of the necessity (McKinsey \& Company 2017).

\footnotetext{
${ }^{1}$ http://www.r-project.ro/conference2017/
} 


\section{Literature Review}

A research design indicates how to plan and conduct empirical research (quantitatively and qualitatively), including: descriptive statistics, mathematics, and popular software tools for analysis (N.J.Salkind 2010). There are many packages available for econometric modeling which have improved and have converged in terms of what is available in each package. The programs can be categorized as: whether they are fully interactive (menu-driven), such as Eviews, or command-driven (so that the user has to write mini-programs). Such packages are often the least flexible, since the menus are fixed, however, EViews has a command-based programming language as well as a click-and-point interface. (Brooks 2014)

Automation changes the activities of all sectors, including finance, as robots and computers can perform routine physical work activities better and more cheaply than humans, being increasingly capable of accomplishing activities that include cognitive capabilities (James Manyika 2017). The analysis of the impact of automation, covering $78 \%$ of the global labor market, the high percentage of time spent on activities with the technical potential for automation by adapting currently demonstrated technology shows a very high potential for automation, in many countries. In figure 1, we can see the high potential for automation in the European countries, in the case of the Finance and insurance sector; when all the sectors all considered, this potential is still high, reaching $50 \%$ in several countries, such as Russia or Italy (McKinsey Global Institute 2017).

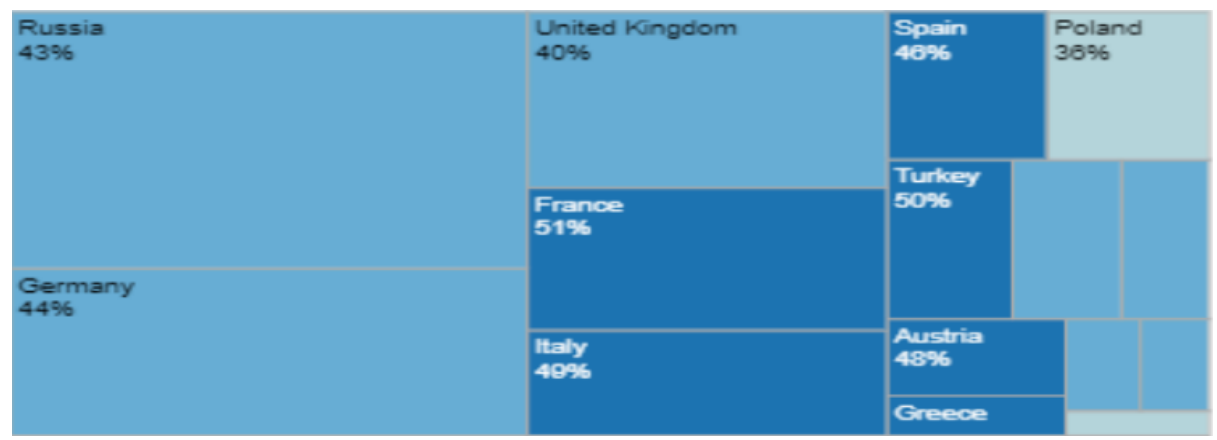

Figure 1: The high potential for automation in the Finance and insurance sector

Source: (McKinsey Global Institute 2017)

Computational econometrics is applied econometric practice, as the development of computational techniques for econometrics (estimation or numerical methods); computer studies (Monte Carlo experiments, genetic algorithms, network studies, or estimation methods like simulated annealing); studies in which the computer does nonlinear estimation of large-scale systems, massive simulations; development of computational environments for econometric studies (GAMS or Stata ) (Belsley and Kontoghiorghes 2009). The General Algebraic Modeling System (GAMS) is used by multinational companies, universities, research institutions and governments in energy and chemical industries, for economic modeling, or agricultural planning, or manufacturing (GAMS n.d.).

Data mash-ups in R can analyze mortgage foreclosures by extracting addresses from a public report, placing them on a map and grouping them by various criteria, such as valuation and other socioeconomic factors (Loukides 2011). Others are starting to use R for data analysis, data manipulation from Oracle databases, reports, data editing, survey estimation and found some problems working with big data sets, also sur ${ }^{2}$ vey sampling as there are surveys with complex sampling designs (Rudys

\footnotetext{
${ }^{2}$ For some reason, the situation of Romania has not been included in this study

${ }^{3}$ Started as a project at the World Bank in the 1970s, GAMS was the first software system to combine the language of mathematical algebra with traditional concepts of computer programming, in order to describe and solve optimization problems (GAMS n.d.).

${ }^{4}$ Stata is an integrated statistical software package with tools for data analysis, data management, and graphics (STATA n.d.)
} 
Madalina Viorica Manu, Ilie Vasile

Contemporary Data Science for Finance Students: A Comparative Study of Essential Features of

Commonly Used Statistical Software

2016). $\mathrm{R}$ has the advantage that allows extensions of functions developed by the user for econometric modeling (Simionescu 2014). Also, if we consider the output from a regression or discriminant analysis, $R$ gives minimal output and stores the results in a fit object for subsequent interrogation by further $R$ functions (Venables, Smith and Team 2016).

\section{Research Methology}

This qualitative research is based on discussions and inputs from PhD students, with respect to the advantages of using $\mathrm{R}$ system - a statistics system or an environment with both classical and modern statistical techniques (R 2009).

\subsection{Considerations}

RStudio is recommended for beginners as no prior knowledge/ experience with R/ RStudio are required. The features of RStudio include, besides the increased productivity of $R$ users (Benjamin S. Baumer 2017):

- Integrates tightly reproducible analysis tools,

- Packages, such as the very useful and also very popular ggplot2 for creating graphics (based on the data input, maps variables to aesthetics, etc.) (Hadley Wickham n.d.);

- Helps avoid error-prone "cut-and-paste" workflows;

- supports authoring HTML, PDF, Word Documents, and slide shows, and interactive graphics (with Shiny and ggvis);

- code-completion,

- The open Source Edition of RStudio Executes R code directly from the source editor, jumps to function definitions, has interactive debugger to diagnose and fix errors quickly (RStudio 2018).

However, for the students in Finance, using MATLAB' Financial Toolbox ${ }^{\text {TM }}$ functions for mathematical modeling and statistical analysis of financial data, can help optimizing portfolios of financial instruments, optionally take into account turnover and transaction costs, estimate risk, analyze interest rate levels, price equity and interest rate derivatives, and measure investment performance. Time series analysis functions help the user perform transformations or regressions with missing data and convert between different trading calendars and day-count conventions (The MathWorks, Inc. 2018). In figure 2 below, we can see the steps of portfolio optimization using the Portfolio object in Financial Toolbox ${ }^{\mathrm{TM}}$, in an example of MATLAB Portfolio Optimization against a benchmark.

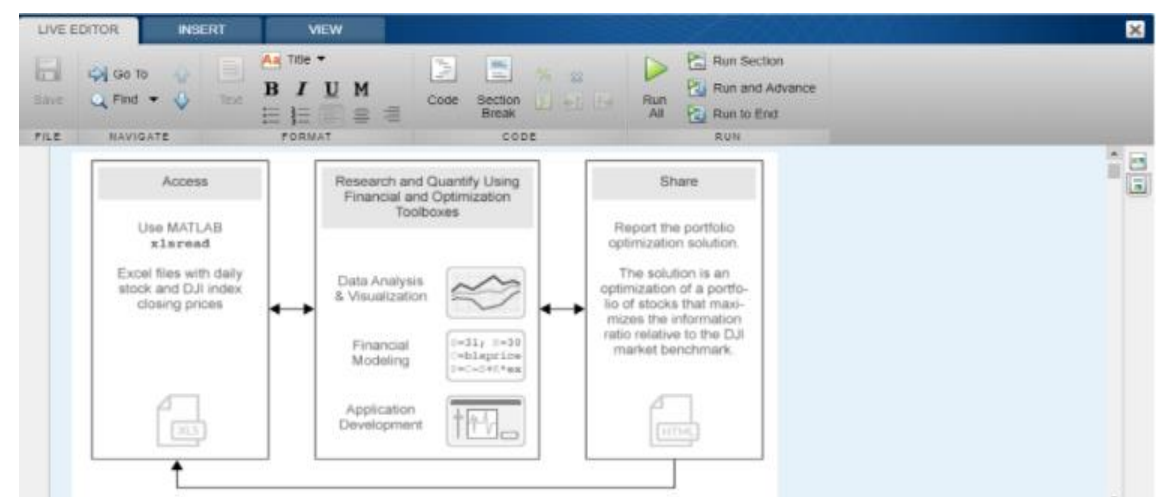

Figure 2: Performing portfolio optimization against a benchmark in MATLAB

Source: (The MathWorks, Inc. 2018) 
Madalina Viorica Manu, Ilie Vasile

Contemporary Data Science for Finance Students: A Comparative Study of Essential Features of

Commonly Used Statistical Software

In table 1 , we summarized several traits of these systems.

Table 1: Comparison

\begin{tabular}{|c|c|c|c|c|}
\hline \begin{tabular}{|l|} 
The General \\
Algebraic \\
Modeling System \\
(GAMS)
\end{tabular} & Stata & $R$ & $S$ & SAS \\
\hline $\begin{array}{l}\text { Algebraic } \\
\text { modeling - the } \\
\text { most productive } \\
\text { way of } \\
\text { implementing } \\
\text { optimization } \\
\text { models and } \\
\text { decomposition } \\
\text { methods for } \\
\text { optimization } \\
\text { problems }\end{array}$ & $\begin{array}{l}\text { standard methods: } \\
\text { Basic tabulations } \\
\text { and summaries, } \\
\text { Case-control } \\
\text { analysis, ARIMA, } \\
\text { ANOVA and } \\
\text { MANOVA, Linear } \\
\text { regression, Time- } \\
\text { series smoothers, } \\
\text { Generalized linear } \\
\text { models (GLM), } \\
\text { Cluster analysis, } \\
\text { Contrasts and } \\
\text { comparisons, Power } \\
\text { analysis, Choice } \\
\text { modelling, Sample } \\
\text { selection }\end{array}$ & $\begin{array}{l}\text { regarded as an } \\
\text { implementation of the S } \\
\text { language. Large data } \\
\text { objects usually be read } \\
\text { as values from external } \\
\text { files; minimal output } \\
\text { from a regression or } \\
\text { discriminant analysis; } \\
\text { stores the results in a } \\
\text { fit object for } \\
\text { subsequent } \\
\text { interrogation by R. a } \\
\text { comprehensive set of } \\
\text { statistical tables. } \\
\text { Functions evaluate the } \\
\text { cumulative distribution } \\
\text { function } P(X \leq x) \text {, } \\
\text { function, simulate from } \\
\text { the distribution. The } \\
\text { probability density } \\
\text { function and the } \\
\text { quantile }\end{array}$ & $\begin{array}{l}\text { statistical } \\
\text { analysis - as a } \\
\text { series of } \\
\text { steps, with } \\
\text { intermediate } \\
\text { results being } \\
\text { stored in } \\
\text { objects }\end{array}$ & $\begin{array}{l}\text { advanced } \\
\text { analytics, } \\
\text { multivariate } \\
\text { analyses, } \\
\text { business } \\
\text { intelligence, } \\
\text { data } \\
\text { management, } \\
\text { and predictive } \\
\text { analytics: } \\
\text { mines, alters, } \\
\text { manages, } \\
\text { retrieves data; } \\
\text { statistical } \\
\text { analysis; }\end{array}$ \\
\hline
\end{tabular}

Stata: advanced techniques: Multilevel models, Survival models with frailty, Dynamic panel-data (DPD) regressions, SEM -structural equation modeling, Binary, count, and censored outcomes, ARCH, Multiple imputation, Latent class analysis (LCA), Treatment effects, Survey data, Bayesian analysis, Finite mixture models - FMM

\section{Conclusion and Recommendations}

There are many options for the finance students with respect to software instruments for modeling and analyzing finance phenomena.

However, he/ she can choose the proper tools according to the tasks performed, accessibility of the soft, i.e. R and RStudio are free, or the knowledge of it, for example, Eviews is quite friendly with the help of the Eviews Illustrated tutorial, but it doaes not come free of charge. One common feature of the programming languages studied is that the information input can be done from all kinds of files, including Excel.

\section{References}

- Benjamin S. Baumer, Daniel T. Kaplan, Nicholas J. Horton. Modern Data Science with R. 2017. 
Madalina Viorica Manu, Ilie Vasile

Contemporary Data Science for Finance Students: A Comparative Study of Essential Features of

Commonly Used Statistical Software

https://books.google.ro/books?id=NrddDgAAQBAJ\&dq=data+science\&hl=ro\&source=gbs_n avlinks_s (accessed 2018).

- Briand, Genevieve, and R. Carter Hill. Using Excel for Principles of Econometrics. New York: John Wiley and Sons, 2011.

- Brooks, Chris. Introductory Econometrics for Finance. Cambridge: Cambridge University Press, 2014. Crossref

- Edited by David A. Belsley, E. J. Kontoghiorghes. "Preface." In Handbook of Computational Econometrics. Chippenham, Wiltshire: John Wiley \& Sons, 2009.

- Essnet Validat Foundation. "Methodology for data validation 1.0." 062016. https://ec.europa.eu/eurostat/cros/system/files/methodology_for_data_validation_v1.o_re v_2016_06_final.pdf (accessed 01 2018).

- Fernandez, Pablo. Company valuation methods. Madrid, 2017.

- GAMS. About the Company. GAMS. n.d. https://www.gams.com/about-the-company/ (accessed 12 2017).

- Hadley Wickham, Winston Chang. Overview. n.d. http://ggplot2.tidyverse.org/ (accessed 01 2018).

- Huber, Chuck. Data management made easy. STATA. 11 15, 2017. https://blog.stata.com/ (accessed 01 2018).

- James Manyika, Michael Chui, Mehdi Miremadi, Jacques Bughin, Katy George, Paul Willmott, and Martin Dewhurst. Harnessing automation for a future that works. 012017. https://www.mckinsey.com/global-themes/digital-disruption/harnessing-automation-for-afuture-that-works (accessed 2018).

- Loo, Mark van der. "Statistical Data Cleaning with R." Use of R. Bucharest, 2017.

- Loukides, Mike. What Is Data Science? 042011.

- Mathworks. n.d. https://de.mathworks.com/videos/matlab-student-overview-89557.html (accessed 01 2018).

- McKinsey \& Company. McKinsey Quarterly. New York, 2017.

- McKinsey Global Institute. Where machines could replace humans - and where they can't (yet).

01

2017. https://public.tableau.com/profile/mckinsey.analytics\#!/vizhome/InternationalAutomation/ WhereMachinesCanReplaceHumans (accessed 2018).

- N.J.Salkind, editor. Encyclopedia of Research Design. California, USA: SAGE Publications, 2010. Crossref

- Python Software Foundation. 2018. https://docs.python.org/3/tutorial/index.html (accessed 01 2018).

- Quantitative Micro Software, LLC. EViews 6 Student Version. 2007.

- R for Data Science. n.d. http://r4ds.had.co.nz/introduction.html (accessed 012018 ).

- R Project R-omania Team. n.d. http://www.r-project.ro/.

- R. What is R? 2009. https://www.r-statistics.com/page/16/ (accessed 01 2018).

- RStudio. n.d. https://www.rstudio.com/products/rpackages/ (accessed 012018 ).

- RStudio Desktop. 2018. https://www.rstudio.com/products/RStudio/ (accessed 012018 ).

- Rudys, Tomas. "Use Of $\mathrm{R}$ in Statistics Lithuania." (Romanian Statistical Review), no. 2 (2016).

- SAS. About SAS. SAS. n.d. https://www.sas.com/en_us/company-information.html\#history (accessed 01 2018).

- Simionescu, Mihaela. Modelare economică în Matlab, R și Eviews. București: A.S.E., 2014.

- STATA. Why Stata. n.d. https://www.stata.com/why-use-stata/ (accessed 01 2018).

- The MathWorks, Inc. Financial Risk Management: Improving Model Governance with MATLAB. 2018. https://www.mathworks.com/campaigns/products/offer/financial-riskimprove-model-governance-white-paper.html (accessed 2018).

- Financial Toolbox. 2018. https://www.mathworks.com/help/finance/getting-started-withfinancial-toolbox.html (accessed 2018). 
Madalina Viorica Manu, Ilie Vasile

Contemporary Data Science for Finance Students: A Comparative Study of Essential Features of

Commonly Used Statistical Software

- Portfolio Optimization Against a 2018. https://www.mathworks.com/help/finance/examples/portfolio-optimization-against-dowbenchmark.html (accessed 2018).

- TIOBE. TIOBE Index for February 2018. 02 2018. https://www.tiobe.com/tiobe-index/ (accessed 02 2018).

- Venables, W. N., D. M. Smith, and R Core Team. "An Introduction to R." 2016. https://cran.rproject.org/doc/manuals/r-release/R-intro.pdf.

- Webb, Allen. McKinsey Quarterly 2017 Number 4: Overview and full issue. 2017. https://www.mckinsey.com/business-functions/mckinsey-analytics/our-insights/mckinseyquarterly-2017-number-4-overview-and-full-issue (accessed 2018). 